\title{
AMÉRICO FERRARI \\ (1929-2016)
}

El $1^{\circ}$ de marzo nos dejó Américo Ferrari, uno de los más distinguidos miembros de la Academia Peruana de la Lengua y admirado amigo. Ya no gozaremos ni de sus conocimientos ni de su amable figura. Su conversación apasionada parecía siempre la de un entusiasmado y despeinado muchacho, y así he de recordarlo siempre ahora que ha tocado su fin.

La primera noticia que tuve de Américo fue su espléndida introducción a la Obra poética completa de César Vallejo editada por la viuda del poeta en 1968. Como consecuencia de esta edición, a la que al poco tiempo se sumó El universo poético de César Vallejo (1972), es decir, el mejor y más profundo estudio que existe sobre la poesía del poeta trujillano, a Américo se le conoce, principalmente, como un crítico vallejiano. La incuria en el ámbito de nuestra lengua ha reducido injustamente la riqueza y complejidad de la obra literaria de Américo Ferrari.

Al poco tiempo de la publicación de estos libros, lo conocí personalmente en Lima, donde venía con cierta regularidad, gracias al poeta Manuel Moreno Jimeno. Nos vimos siempre durante estos cortos viajes intermitentes y su amistad la cuento entre las pocas verdaderas que he gozado en mi vida. Uno puede verse todos los días con la misma persona y esta puede ser solo un sencillo conocido. Con Américo la amistad no era difícil por su sencillez y don de gentes y porque, además de otros amigos comunes, nos unía el interés por la Poesía y la lectura de ciertos autores. 
Es necesario, ahora que nos ha dejado, hacer un recuento sucinto para presentar al verdadero Américo Ferrari cuya obra excede, por cierto, únicamente a la de un crítico vallejiano. A un lector avisado, la lectura de cualquier estudio, artículo o mera nota de Américo Ferrari, se le revela que quien trataba o se acercaba a la Poesía como él lo hacía, no era un simple crítico literario sino un poeta comprometido no solo con su propia obra de creación poética, sino también con la difusión de la poesía que frecuentaba a través de los estudios que escribió sobre distintos autores.

Américo Ferrari nació en Lima en 1929 donde estudió Filosofía en la Universidad Nacional Mayor de San Marcos. En principio, su salida del Perú tuvo que ver con un componente político gracias al consabido dictador de turno que jamás ha faltado en el Perú. Así, continuó sus estudios de Filosofía en la Universidad de la Sorbona, en París, donde obtuvo su licenciatura en 1955. Siguió también estudios de Literatura en la misma universidad, donde obtuvo la licenciatura de Letras en 1962 y el doctorado en 1970. Obtuvo el doctorado en Filosofía y Letras en la Universidad Nacional Mayor de San Marcos el año siguiente. Luego, durante diez años, fue profesor de Literatura en la Universidad de la Sorbona para luego desempeñarse como profesor en la Escuela de Traducción e Interpretación en la Universidad de Ginebra, entre 1976 y 1995, año en que se jubiló. Enumerados, en forma escueta, los principales datos de su transcurso vital y del peregrinaje académico que sustenta su labor desarrollada, debe hablarse sobre 
la obra de Américo en el campo de la literatura: en primer lugar, el de la Poesía.

El ejercicio de la Poesía es cada vez más azaroso para el poeta que la escoge como ideal supremo durante su vida. Por motivos de supervivencia, el poeta se ve precisado a realizar labores que se encuentran muchas veces lejanas de su vocación verdadera. En estos tiempos de penuria y turbulencia, el poeta se ve cada vez más constreñido en su accionar. Así, muchas veces se dedica a la enseñanza como lo hizo Américo. La docencia es una profesión agradable pero por momentos puede ser horrible. Jamás olvidaré sus quejas de tener que dictar clases sobre el insoportable Miguel Ángel Asturias cuando le otorgaron el Premio Nobel de Literatura. Pero la historia nos enseña que la labor de los poetas se desarrolla como un manantial oculto en las sociedades que solo advierten su importancia con el paso de los años: la poesía puede no ser esencial para algunos individuos pero es esencial como expresión genuina de la cultura de los pueblos. Ignoro si es simple leyenda, simple invención o simple anécdota, pero se cuenta que el poeta norteamericano Ezra Pound afirmó alguna vez que con el paso del tiempo sus lectores se preguntarían quiénes eran ese Mussolini y ese Stalin citados por él en sus poemas. Creo que no se trataba de simple orgullo de poeta. ¿Quién conoce a los políticos que cita Dante en su Commedia? La Poesía, pues, es un manantial que corre oculto en nuestras sociedades, pero que gracias a la energía espiritual que los poetas depositan en ella tiene posibilidades de trascender y de perdurar. 
Los políticos quedan segados y olvidados en poco tiempo. El poeta puede constituir quizá una figura invisible o incómoda, por sus innegables características de libertad y de rebeldía a toda prueba, para muchos de sus contemporáneos, pero siempre constituye el legado más apreciado de las generaciones por venir. Son, pues, verdaderamente, como afirmaba Shelley «los legisladores no reconocidos del mundo». La política es solo lo urgente; la poesía, lo verdaderamente importante.

Américo Ferrari, antes que todo, fue un poeta que pertenece a esa exuberante generación poética peruana conocida como la del 50. Sin embargo, solo empezó a publicar sus poemas en libros tardíamente en 1972, en España, por medio de dos plaquettes de reducidísimo tiraje: El silencio de las palabras y Espejo de la ausencia y la presencia. Antes solo había publicado parcamente poemas en publicaciones periódicas del Perú y del extranjero. Fue, pues, siempre un poeta discreto que únicamente daba a conocer lo que estimaba realmente acabado. En el Perú, me tocó a mí el honor de ser el editor de sus dos libros siguientes Las metamorfosis de la evidencia (1974) y Tierra desterrada (1980). Su libro posterior, Figura para abolirse, apareció en Lisboa en 1985 y La fiesta de los locos en Barcelona en 1992. Luego, toda la poesía de Américo se recogió en Barcelona en el volumen titulado Para esto hay que desnudar a la doncella. Obra poética (1949-1997) (1998) en la prestigiosa colección El Bardo. Su libro poético postrero se publicó aquí en Lima con el título de Casa de nadies (2000) bajo el sello de Gonzalo Pastor Editor. 
El título escogido para recopilar su obra poética es un tanto subversivo: Para eso hay que desnudar a la doncella. Se trata de un tema inserto en la tradición moderna de nuestra lengua. Es evidente la alusión al famoso poema de Juan Ramón Jiménez «Vino, primero, pura, / vestida de inocencia». El poema de Juan Ramón Jiménez no hace sino indicar su preferencia por la poesía sencilla, carente de adornos que solo echan a perder lo natural de la expresión poética así como los adornos afectan la hermosura de una mujer. Américo tomó esta idea de la poesía escueta, esencial, carente de afeites para caracterizarla como fundamento de su propia poética. Efectivamente, sus poemas, como que carecieran por completo de retórica, lo cual es una paradoja en el arte de la poesía cargado espontáneamente de usos y elementos retóricos para poder sustentarse y muchas veces existir. $\mathrm{Y}$ es que la poesía de Américo, a veces tan difícil de penetrar y falto de halago verbal, nos presenta el mundo tenso y a menudo alucinante de un contemplador y un oyente de las más secretas palpitaciones del planeta. La visión de Américo Ferrari se da por lo general en su poesía de dos formas: mediante su acercamiento a lo absoluto o vertida en un tono irónico. Es decir, de lo universal e impalpable a lo concreto. Por eso creo que el acto de la lectura de un poema de Américo Ferrari rebasa muchas veces la experiencia racional. Así como nunca acabamos de comprender por qué una explosión nos estremece o por qué la oscuridad sumada a los ruidos nocturnos, en algún momento, pueden causarnos pavor, en la lectura de la poesía de Américo 
Ferrari puede haber momentos en que nuestros cabellos se ericen o se produzca en nosotros la sensación de abismo. La obra poética de Américo está aún por descubrirse en el Perú.

Otra de las facetas literarias de Américo Ferrari es la del traductor de poesía. La traducción es considerada, por lo general, como una tarea menor dentro de los trabajos literarios, pero la traducción poética se diferencia tanto de la simple traducción, como se diferencia la escritura de un poema de, digamos, un artículo o una narración, y esto hay que recalcarlo porque muchas personas no lo saben $y$, hay veces, lo ignoran hasta los mismos poetas. Cuando la traducción roza con la poesía, constituye un arte. Pues bien, como traductor fiel e inspirado, Américo se vertió en traducciones exquisitas de dos poetas capitales de la lengua alemana: Novalis y Georg Trakl. Del primero tradujo los Himnos a la noche y los Cánticos espirituales; de Georg Trakl, el estremecedor libro Sebastián en sueños. También ha traducido el difícil poemario Amor a muerte del gran poeta peruano César Moro. Consideramos esta labor de traducción una extensión de su propia obra poética, ya que sabemos, al momento de su lectura, que sus traducciones solo pueden haber sido realizadas por un poeta verdadero.

Como crítico literario, Américo publicó cuatro libros de estudios literarios: El universo poético de César Vallejo (Caracas, 1972; y Lima, 1997), Los sonidos del silencio. Poetas peruanos del siglo XX (Lima, 1990), El bosque y sus caminos. Estudios sobre poesía y poética hispanoamericanas (Valencia, 1993) y la summa de estos tres últimos con numerosas adiciones y algunas 
supresiones en La soledad sonora: Voces poéticas del Perú e Hispanoamérica (Lima, Pontifica Universidad Católica del Perú, 2003).

Como crítico literario Américo Ferrari poseía dos características fundamentales e imprescindibles en quienes se dedican a esta labor: penetración y profundidad. Además, Américo se caracterizaba por su claridad expositiva, una metodología ejemplar y una seguridad que le permitía el acceso a puntos que difícilmente advertiríamos si no contáramos con sus análisis. Se trata, pues, de libros de crítica literaria en los que Américo asumía un papel que ojalá siguieran otros críticos. Me explico: gran parte de los críticos literarios hoy en día asumen un rol pontificador, utilizan terminologías abstrusas y escriben con un desencanto estilístico que los hace ilegibles o de penosa lectura. Además, parecen más interesados en la teoría que en la obra literaria a la cual se aproximan. Como la crítica literaria depende de otros textos creativos, lo que, por lo general, busca un lector es un libro que lo ayude a comprender mejor al autor que ya leyó o que quiere leer. El posible lector no quiere leer a un crítico que se luzca con una teoría pomposa, sino a otro escritor que lo ayude en su lectura, que esclarezca lo que para él es incomprensible o poco comprensible. Pero, entiéndase que no quiero decir que en un crítico solo debe destacarse la comprensión del tema, del poema o del relato escogido sino que esta es solo una de sus tareas: explicar. Una buena explicación nos lleva al objetivo de lo que finalmente cuenta en una lectura: la comunicación de la experiencia primordial, esencial y universal 
que transmite toda gran obra literaria. Por eso la lectura de un estudio literario escrito con las galas literarias de un escritor verdadero puede poseer muchas veces mayor fascinación que un cuento o una novela.

La virtud de los libros de Américo Ferrari se extrema en dos polos: una poesía difícil que revela insospechados mundos expresivos y una gran penetración crítica en sus estudios literarios. Como persona, Américo nunca ponía sus libros bajo los ojos de sus amigos, solo los obsequiaba con una discreción admirable, como quien casi no nos daba nada. En esta triste despedida solo quiero recordar tres de sus conmovedores endecasílabos:

por eso despidámonos hermano

y finjamos en signos la partida

ya no nos queda sino voz dolida

RicARDO SILVA-SANTISTEBAN 